\title{
Conceptual clarification of evolution as an interdisciplinary science
}

\author{
Susan Hanisch ${ }^{1,2,3}$ \\ susan.hanisch@eva.mpg.de \\ Dustin Eirdosh ${ }^{1,2,3}$ \\ dustin.eirdosh@eva.mpg.de
}

1 Max Planck Institute for Evolutionary Anthropology, Department of Comparative Cultural Psychology

2 Global ESD

3 EvoLeipzig

\section{Project Overview}

\author{
Teaching evolution as an interdisciplinary science \\ Project page on OSF: https://osf.io/u6rd5/
}

Evolutionary theory in the 21 st century has been embraced, albeit with varying degrees of controversy and consensus, across wide ranging disciplines. From biology and anthropology, to medicine, psychology, economics, sustainability science, computer science, and many more, core concepts of heritable variation and selection have been utilized by scientists across academia to understand change in the natural and social world. Evolution education, however, remains largely a disciplinary endeavor of biology education, and educators are left with little guidance on interpreting the broader interdisciplinary applications of modern evolution science discourse. This project takes a historical and sociological view on interdisciplinary conceptions of evolutionary theory and argues that, while legitimate scientific controversies abound, it is exactly these interdisciplinary conceptions of evolutionary theory, and the resulting controversies, that may hold significant learning potential for addressing some of the persistent challenges facing evolution education more broadly.

This paper, Hanisch \& Eirdosh (2020a), aims to provide evolution educators with a short review of current discourse in evolution science and a conceptual clarification of core concepts in evolutionary theory, in the service of promoting deeper and transferable understanding of these concepts. In Hanisch \& Eirdosh (2020b), we outline a set of hypotheses about the educational potential of teaching evolution from a more generalized, interdisciplinary conception, addressing a range of enduring challenges in evolution understanding and acceptance. In Hanisch \& Eirdosh (2020c), we provide some examples of current evolution education discourse, educational materials, and assessment tools that represent a number of challenges regarding how evolution is frequently conceptualized in evolution education. Based on the outlined challenges to evolution understanding and acceptance hypothesized to stem from a gene-focused conceptualization, together with the 
outlined opportunities hypothesized to be capable of addressing these challenges through teaching evolution from a more generalized, interdisciplinary conceptualization, we propose that the evolution education community should focus more strongly on investigating these avenues. In Hanisch \& Eirdosh (2020d), we address a range of possible or existing objections that might hinder the advancement of such a research program.

\section{Abstract}

Evolutionary theory in the 21 st century has been embraced, albeit with varying degrees of controversy and consensus, across wide ranging disciplines. From biology and anthropology, to medicine, psychology, economics, sustainability science, computer science, and many more, core concepts of heritable variation and selection have been utilized by scientists across academia to understand change in the natural and social world. This article aims to provide evolution educators with a short review of current discourse in evolution science and a conceptual clarification of core concepts in evolutionary theory, in the service of promoting deeper and transferable understanding of these concepts in evolution education.

\section{Introduction}

Evolution science, as a broad field of study, is continuously advancing and developing, with new theoretical considerations based on new methods and empirical findings being added over the years and decades into a more nuanced understanding of how evolution operates across the biological world. Sometimes these advances challenge popular conceptions of evolution by natural selection as solely acting on individual organisms within populations.

For example, advances in cancer research have been made by viewing the body as itself a population of cells and applying evolutionary approaches to how cancerous cells can spread within the body: "An appreciation that cancer clones develop, or evolve, in the context of a complex tissue ecosystem has transformed our understanding of cancer biology and highlighted the need for more innovative approaches to therapy that can thwart evolutionary resilience (...). An evolutionary logic pervades all major areas of cancer sciences including causation, cancer clone development and resistance to therapies." (Greaves, 2018).

However, even scholars beyond traditionally biological fields have begun to use concepts from evolutionary theory to explain observable variation and change of characteristics in a diversity of populations. The fields of evolutionary and behavioral economics have begun to integrate generalized concepts of variation, selection, and retention to explain change in social-economic systems, including change in human economic behavior (Beinhocker, 2013; Bowles \& Gintis, 2011; Hodgson \& Knudsen, 2010). Archeologists and cultural evolution scientists have begun to use methods and concepts from evolutionary biology and population genetics to help investigate and understand the variation and spread of human cultural traits over human evolutionary history (Cavalli-Sforza \& Feldman, 1981; Mesoudi, 2011; Shennan, 2009; Richerson \& Boyd, 2005). Sustainability scientists have in turn begun to use these methods of cultural evolution to study the spread of sustainable resource use 
and other sustainability relevant cultural traits in human communities across the world (Kline et al., 2018; Waring et al., 2017). Historians are using evolutionary theory to model and interpret societal trajectories across history (Turchin, 2010). Psychologists and behavioral scientists build on an evolutionary understanding of human behavior, language, and learning to address the prevention of mental health issues and various problems of public health (Hayes et al., 2017; Wilson et al., 2014). Evolutionary scientists and organizational psychologists are collaborating by "using evolutionary science to build productive, equitable, and collaborative groups" (Atkins et al., 2019). Computer scientists develop and make use of evolutionary algorithms in machine learning, informed by processes of biological evolution (Valiant, 2013). Each of these interdisciplinary developments in turn, have greatly helped to advance conceptual understanding of evolutionary theory, for example through the development of evolutionary game theory and agent-based modelling methods (Gintis, 2009; McElreath \& Boyd, 2007; Rice, 2004).

Another way to observe the increasing interdisciplinary nature of evolution science is to look at how the often cited mantra that "Nothing in biology makes sense except in the light of evolution" (Dobzhansky, 1973), has been expanded upon over the years, indicating how evolutionary theory is being applied to a broad range of phenomena, e.g.:

- "Nothing in cancer makes sense except ... [in the light of evolution]" (Greaves, 2018)

- "Nothing about culture makes sense except in the light of evolution" (Boyd \& Richerson, 2005)

- "Nothing about policy makes sense except in the light of evolution" (Wilson \& Johnson, 2016)

- "Nothing in economics makes sense except in the light of human social evolution", "Nothing in the social sciences makes sense except in the light of human social evolution." (Fix, 2019)

- "Nothing in human affairs-including much of economic and socio-political behavior-makes sense except in the light of evolution" (Rees, 2010)

- "Nothing in biology makes sense except in the light of evolution," needs to be expanded to include our own species, including our cultural and behavioral diversity; and this expansion needs the same positive connotation that the dictum already has for biologists." (Wilson et al., 2014)

What all of these developments indicate is that evolution has become conceptualized more broadly as a theory of change that helps understand variation and distribution of heritable traits of various kinds, rather than being restricted to rather gene-focused conceptualizations of the so-called Modern Synthesis.

In this article, we review some of the history and sociology of evolution science in recent decades to highlight how scientists across various disciplines, within biology as well as within other fields such as anthropology, archeology, psychology, history and sociology, go about studying their respective phenomena by employing the concepts and methods of evolutionary science. Specifically, we draw on three emerging fields of discourse - the Extended Evolutionary Synthesis (EES), Cultural Evolution Science (CES), and Contextual Behavioral Science (CBS), all of which draw upon new thinking about classic concepts in evolution science to advance understanding of diverse phenomena of interest. We do not 
claim that these fields represent consensus science, or that they are without external critics or internal disagreements, only that, taken as a whole, there is an emerging case to be made that general evolution education could benefit by engaging a more generalized understanding of key concepts in evolution science.

Based on these developments, we offer a conceptual clarification of key concepts in evolutionary theory in the form of an analogy map, comparing conceptualizations as they are understood from a gene-focused versus a more generalized, phenotype-focused, interdisciplinary perspective.

\section{History and sociology of evolutionary science}

In this section, we briefly outline some key developments in scientific discourse around the nature of evolution, particularly within the last two to three decades, with the aim of pointing out possible implications for evolution education.

In Darwin's time, nothing concrete was known about the specific mechanism of variation that created the diversity of phenotypes within and across populations, nor about the specific mechanism of inheritance that made offspring resemble their parents. Thus, Darwin formulated his theory of evolution through natural selection in general terms, without specifying the mechanisms of variation/modification and inheritance.

Evolutionary theory in the second half of the 20th century has been greatly influenced by the Modern Synthesis (MS; Huxley, 1943) which incorporated insights from molecular biology and genetics into the theory of evolution by natural selection. The discovery of DNA and the mechanism of variation through random mutations in the DNA code, as well as the mechanism of genetic inheritance through biological reproduction seemed to make concrete how Darwin's theory of natural selection works.

In recent decades, three broad lines of investigation and discourse have complexified or challenged this gene-focused conceptualization of evolution: the discussion around the need for an extended evolutionary synthesis, the science of cultural evolution, and contextual behavioral science. To our knowledge, with some exceptions (e.g. Apodaca et al., 2019), these perspectives appear to be not currently part of the broader discourse on how to teach evolution science, particularly in secondary school and general education more broadly.

There are a multitude of conceptual overlaps between these lines of discourse and research, but for the purpose of this paper, it is worth introducing these three lines separately. This is because they may have slightly different implications for the evolution education community, implying different needs for debate and different opportunities concerning the teaching of evolution. For example, cultural evolution tends to focus more on the mechanisms of population change in our own species (noting that many cultural evolutionary scientists do also study cultural phenomena in other species), while the debate about an extended evolutionary synthesis tends to be about a broader problem of how to conceptualize the theory of evolution across biology. They may thus have different implications regarding the teaching of human evolution vs. teaching about evolution in general. Contextual behavioral 
science is more concerned with applying evolutionary principles to the evolving cognitive-behavioral repertoires of individuals and groups, which may have implications regarding social-emotional learning.

\section{Perspectives from the debate about an Extended Evolutionary Synthesis}

In the last decade, many publications have been put forward that indicate an increasing call for expanding, extending or restructuring the generalized theory of evolution beyond the conception stemming from the MS. Examples include Pigliucci (2009), Pigliucci \& Müller (2010), Laland et al. (2014, 2015), Müller (2017), and Huneman \& Walsh (2017).

These calls come from biologists across various sub-disciplines, including evolutionary developmental biology (evo-devo), behavioral biology, ecology, systems biology, genetics, complexity science and molecular biology. A core argument is that methodological advances and empirical findings in these disciplines in the last two-three decades have greatly complexified our understanding about the possible mechanisms of change in populations over time and seem to challenge a number of commonly held assumptions about the nature of evolution stemming from the formulation of the MS. Examples are: West-Eberhard (2003) regarding the role of developmental plasticity in evolution; Odling-Smee et al. (2003) regarding the role of niche construction and niche selection, i.e. the active role of organisms changing or choosing their environments, in evolution; Jablonka \& Lamb (2005) regarding the role of genetic as well as epigenetic, behavioral and symbolic variation and inheritance in evolution; Noble $(2006,2015)$, Oyama et al. (2001) and Bapteste \& Huneman (2018) regarding the decentralized and complex nature of causality in development and evolution; and Sober \& Wilson (1998) regarding the role of selection operating at multiple levels in evolution.

One way to characterize a broader or extended conceptualization of evolution is a more explicit integration of complex systems dynamics across phylogenetic and developmental timescales, describing the changes that arise from interactions among many - more or less heritable - parts within these systems on different levels and time frames.

For example, in the MS, natural selection is frequently conceptualized as a unidirectional process from an external environment to organisms in a population, leading to adaptations. However, many biologists have come to the view that natural selection is better understood as emerging from complex interactions between (abiotic, biotic, social, cultural) environmental factors, organism behaviors and other traits, and genes. Similarly, the emphasis on genes in the expression of phenotypes in the MS may hinder the understanding of an often much more complex causality of phenotypes. Proponents of a developmental systems view regard evolution as "not a matter of organisms or populations being molded by their environments, but of organism-environment systems changing over time" and "every trait is produced by the interaction of many developmental resources. The gene/environment dichotomy is only one of many ways to divide up these interactants." (Oyama et al., 2001). Similarly, Bapteste \& Huneman (2018) emphasize that "nothing on Earth evolves and makes sense in isolation, thereby challenging the key assumption of the Modern Synthesis 
framework that targeting the individual gene or organism (even when in principle knowing that it is part of a set of complex interactions) allows us to capture evolution in all its dimensions. Since the living world evolves as a dynamic network of interactions, we argue that evolutionary biology could become a science of evolving networks, which would allow biologists to explain organisational complexity, while providing a novel way to reframe and to unify evolutionary biology." (emphasis added). Similarly, Davies (2014) proposes that the icon of biology in the 20th century, the DNA double helix, may in the 21st century be replaced by the feedback loop, since "it would be a much more universal symbol of how life works at all of its scales and levels."

Thus, these views promote a decentralized view of biological systems and apply it to evolutionary (as well as developmental) processes, informed by concepts and methods of systems biology or complexity science. Since one set of challenges in evolution education relates to the difficulty for students to understand this complexity, and resulting notions of genetic determinism or natural selection as an event, this systems view may also be a productive direction for evolution education (see Hanisch \& Eirdosh, 2020b).

Current debates around extending the conception of evolutionary theory revolve around empirical and conceptual issues as well as issues concerning historic accounts about the development of evolutionary theory (Fabregas-Tejeda, 2019; Lewens, 2019). Because of this, the sociology of this debate is rather complex. Different opinions and standpoints exist about what exactly does or does not need to change or be added to an extended theory of evolution, whether talk about a "paradigm shift" is justified, whether one overall theory of evolution is even possible, or whether a more pluralistic framework is called for simply because biologists of different sub-disciplines study different phenomena (Lewens, 2019; Love, 2017; Pigliucci, 2009).

Some biologists who are opposed to the EES claim that "all is well" with the current conceptualization of evolution and that "We, too, want an extended evolutionary synthesis, but for us, these words are lowercase because this is how our field has always advanced." (Wray et al., 2014). The argument is that concepts such as niche construction, developmental plasticity and inclusive inheritance beyond the genome already receive their due attention in current evolutionary theory (Wray et al., 2014).

The debate is then somewhat about the degree of emphasis that such additional concepts should receive in the diverse corpus of evolutionary theory. All sides largely agree that part of this argument will be dependent on the amount of empirical evidence about the prevalence and importance of these mechanisms across phenomena in biology (Lewens, 2019; Wray et al., 2014). However, proponents that call for the explicit inclusion of these possible mechanisms point out that there is already a very significant evidence base across biology regarding the role of niche construction, developmental plasticity, and inheritance of phenotypes through different mechanisms beyond genetic inheritance, to justify their inclusion in evolutionary theory.

A metaphor borrowed from Arthur et al. (2012; cited in Ciarrochi et al., 2016) highlights this concern about degrees of emphasis: "Suppose a nutritionist had written a book about the need to eat porridge every day, and then concluded with a couple of paragraphs about how 
porridge is not enough but only works as part of a balanced diet." In this context, calls for an extended evolutionary synthesis are partly a concern with the "porridge" of genetic variation, genetic inheritance, unidirectional accounts of selection from environment to organism, or the individual being the centrally important level at which selection occurs, while in reality, the evolution of particular biological phenomena can proceed through a much more varied set of causal mechanisms, in much more complex ways, on various different levels. We are arguing that evolution education could be enriched by a more diverse diet of complex causation.

In this regard, some point out that the characterization of evolutionary theory in educational materials is one line of evidence that a rather restricted, gene-focused view of evolution still prevails. Müller (2017) states that "While documenting numerous empirical and theoretical advances, at the level of core assumption most current textbooks on evolution, whether explicitly or implicitly, still offer a theoretical framework that is largely based on the MS of the 1930s and 1940s." Our snapshot of current evolution education perspectives and materials (Hanisch \& Eirdosh, 2020c) similarly indicates an emphasis on gene-focused characterizations of concepts such as variation and inheritance that is then applied across biological phenomena. It would seem that this point rather favors the argument made by proponents of an explicit extension of evolutionary theory, namely that the wealth of possible mechanisms in evolution as well as their complex causal interactions, is buried under a "porridge" of gene-focused conceptualizations.

On the other hand, Baedke et al. (2020) argue that disagreements regarding an extension of evolutionary theory should and can not be resolved by the amount of empirical evidence for either one, since many examples exist in which two different explanations, stemming from either a gene-focused or extended conceptualizations, seem to be equally supported by evidence, thus stifling progress in this debate. Rather, the debate should be based on the question of whether an explanation is more powerful in terms of helping to achieve a particular level of understanding of a phenomenon. The authors point out that explanations stemming from a gene-focused MS conceptualization are more idealized, abstracting out developmental processes and proximate interactions. Such idealization may not be problematic, and may help in understanding broader phylogenetic changes of a range of phenomena, when precision with respect to concrete developmental processes is less of interest. However, they may provide rather limited understanding if the interest is in providing a more concrete account of the role of developmental processes and other proximate mechanisms in particular phenomena.

A metaphor might illustrate the different strengths and weaknesses of these explanatory styles: The idealization and abstraction of processes that characterize the MS make it more like climate science, whose strength it is to tell us about patterns on broader scales of place and time, but who can tell us little about tomorrow's weather; more fine-grained proximate explanations that are emphasised in the EES make it more like weather forecasts, which is more helpful for knowing details of tomorrow's weather at particular places - one of these explanations is not inherently "better" than the other, but helpful for different purposes.

Arguably, for the aim of fostering understanding of evolutionary (and developmental) change in students, idealizations that stem from gene-focused conceptualizations may hinder the 
integration of student experiences of developmental processes and goal-directed behaviors with the abstract concepts these models require. Such idealizations may also wrongfully lead educators to the conclusion that the (idealized, abstracted) conceptualizations of evolution of the MS represent a more fundamental truth - such that processes operating in development have no causal role in evolutionary change, no matter what the phenomenon. Such conclusions affect assessment of evolution understanding, in that students who integrate such processes in evolutionary explanation are thought to have misconceptions about how evolutionary changes happen (see Hanisch \& Eirdosh, 2020b).

Fig. 1 below illustrates and summarizes the notions of a more idealized, gene-focused conceptualization of evolution stemming from the MS and a more generalized conceptualization within EES which integrates more precisely the role of various factors and processes.

(A)

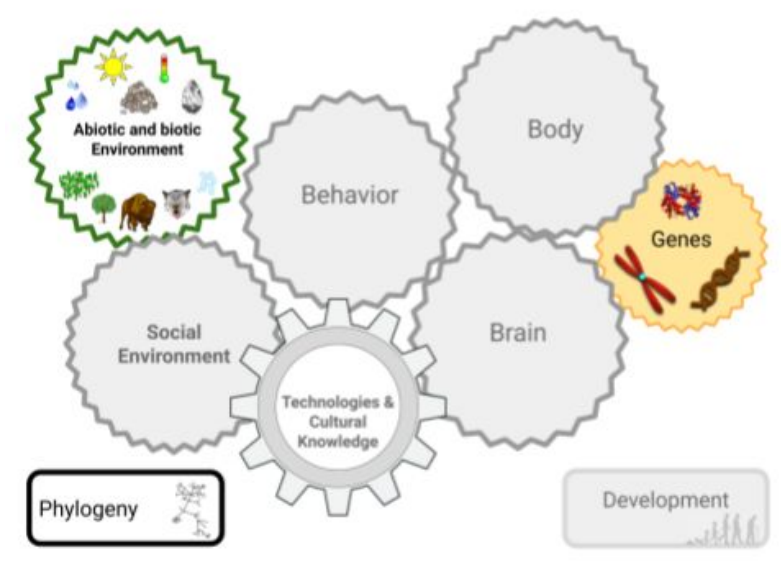

(B)

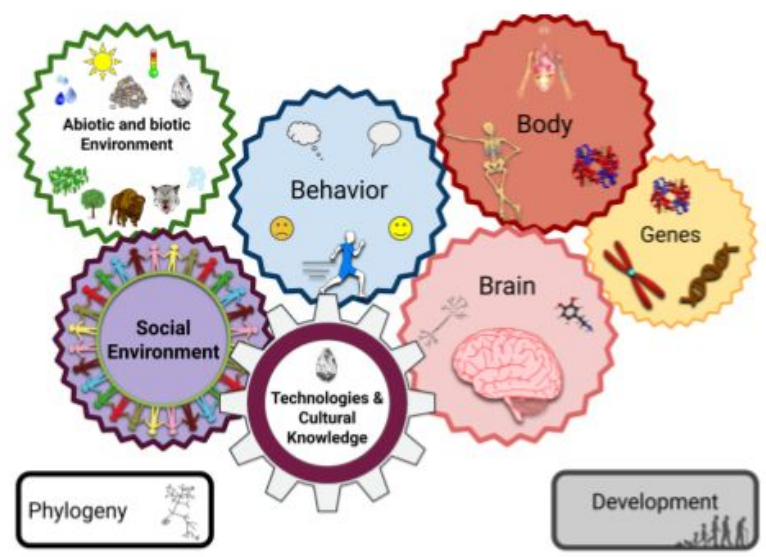

Fig. 1: (A) The causal domains (colored) that are emphasized as relevant for explaining change in populations within a gene-focused view of evolution. Only information storage, transmission and variation in the domain of genes (genetic inheritance, mutations, recombination, genetic drift, sometimes including epigenetics) are framed as relevant. The interaction between genes and environment is often considered unidirectional (environment creates selection pressure on genes, genes in turn do not influence their own selecting environment). Only change that is visible over phylogeny (across biological generations) is considered evolutionary change. Information storage and the generation of novelty in bodies, brains, social and cultural environments, as well as interactions among these domains, including over developmental timeframes, are "abstracted out" or not accounted for, even though they may well influence the selection of genes and the changes in environmental conditions across phylogeny. Special terms are introduced in order to be able to describe "special cases" that appear to deviate from this gene-focused and unidirectional approach and which require the inclusion of some other causal domains and interactions, such as "sexual selection", "artificial selection", "frequency-dependent selection", "kin selection", "coevolution".

(B) The causal domains that are considered relevant for explaining change in populations within a generalized or extended view of evolution. Information, including novel variants of information, can be stored, transmitted and generated not just in genes but in brains, bodies, social, cultural and ecological environments. Behavior plays an important role in organism-environment interactions. Complex reciprocal interactions within and between these domains over various timeframes, including development, are what drives evolutionary change over phylogeny. Special terms can describe the involvement of particular domains and subsets of complex interactions. 


\section{Perspectives from Cultural Evolution Science}

A similar but somewhat independent development has come from scientists studying cultural evolution, in part by successfully applying methods of population genetics to changes in cultural traits. Important pioneering publications are Cavalli-Sforza \& Feldman (1981) and Boyd \& Richerson (1985) as well as more recently, Richerson \& Boyd (2005), Boyd \& Richerson (2005), Richerson \& Christiansen (2013), Mesoudi (2011), Mesoudi et al. (2006), Whiten et al. (2011).

In general, this interdisciplinary field of Cultural Evolution Science (CES) seeks to develop naturalistic explanations about the variation, distribution and spread of cultural traits, such as attitudes, beliefs, knowledge, skills, technologies, norms, and institutions (Acerbi \& Mesoudi, 2015).

CES itself is also characterized by a more nuanced debate, concerning the nature and importance of the mechanisms of selection and transmission of cultural traits and the exact nature of the analogy between biological evolution and cultural evolution. However, it has been pointed out that disagreements may be better understood as differences in emphasis or difference in perspective rather than as inherently conflicting theories of cultural evolution:

"Much of the apparent disagreement might more properly be seen as simple differences in emphasis... The problem comes when these different approaches or emphases are misconstrued as constituting more fundamental theoretical differences. Everyone in fact seems to hold the same basic position: that biological and cultural evolution are similar but different, and that this allows us to draw on biologically inspired methods and concepts where these are warranted, and suitably modify them or discard them when necessitated by specific cultural phenomena. The sole criteria for using methods derived from biology to analyze culture should be whether they can tell us something useful about a specific cultural phenomenon." (Mesoudi, 2007, p. 120, 121)

Furthermore, the underlying agreement is that culture can be understood to evolve according to evolutionary principles: "The logic of natural selection applies to culturally transmitted variation every bit as much as it applies to genetic variation. For natural selection on culture to occur, people must vary because they have acquired different beliefs or values through social learning, this variation must affect people's behavior in ways that affect the probability that they transmit their beliefs to others, and the total number of cultural variants that can exist in the population must be limited in some way. Or, in other words, cultural variants must compete. You can substitute the appropriate genetic terms in this list to recover the standard textbook account of how genes evolve by natural selection. The basic logic is identical. All other things being equal, beliefs that cause people to behave in ways that make their beliefs more likely to be transmitted will increase in frequency." (Richerson \& Boyd, 2005, p. 76).

The quoted paragraphs above reiterate the role of transfer in science, and by extension, in education: the concepts that are central to the mechanisms of change in evolution can be understood in more or less generalized ways. Scientists that use these concepts to study 
change across diverse phenomena engage in transfer of generalizable principles, using their understanding of evolutionary concepts critically with the aim to understand the dynamics of change in a different context of interest.

We argue that, since an overall aim of education is also this ability to transfer concepts, principles and skills in order to solve novel problems (Stern et al., 2017), there may be opportunities to also engage these different perspectives explicitly in the classroom, thereby potentially targeting a number of challenges in evolution understanding as well as motivational challenges due to perceived relevance of evolution to students lives (Hanisch \& Eirdosh, 2020b).

Of interest to the evolution education community may also be the fact that cultural evolution models for the inheritance and spread of human behavioral, cognitive, cultural traits have challenged the notion that certain traits (such as IQ) have a purely genetic basis (Cavalli-Sforza \& Feldmann, 1973). Hence, explicitly integrating the science of cultural evolution may hold potential to also address challenges to evolution understanding and acceptance related to social identity and emotional factors, as well as challenges related to genetic determinism (Hanisch \& Eirdosh, 2020b).

Finally, it is also important to point out that cultural evolution scientists do not only study cultural evolution in our species, but also in other species of animals, such as primates (Whiten \& van Schaik, 2007), mammals (Sheppard et al., 2018), and birds (Aplin, 2019), such that the lessons from cultural evolution science may not just have implications for teaching about human evolution, history, and socio-cultural organization, but for the biology classroom in general.

\section{Perspectives from Contextual Behavioral Science}

A third line of research and discourse that embraces a generalization of evolutionary concepts, with potential relevance to education, is contextual behavioral science.

CBS applies evolutionary principles of variation, selection and inheritance (framed analogously as retention) to behavioral change in individuals and groups, with the aim of understanding, predicting, and influencing human behavior (Hayes et al., 2012). The ultimate aim of contextual behavioral science is to increase human health and psychological flexibility through the application of evolution science.

CBS builds on conceptualizations from B.F. Skinner of learning or behavioral reinforcement as analogous to evolution by natural selection: "operant reinforcement resembles the natural selection of evolutionary theory. Just as genetic characteristics which arise as mutations are selected or discarded by their consequences, so novel forms of behavior are selected or discarded through reinforcement" (Skinner, 1953, p. 430, as cited in Hayes et al., 2017; see Fig.2) 
The following quotes represent further analogical thinking in the field regarding how behavior change within the individual over a lifetime corresponds to change in trait frequency in a population over phylogeny:

"The consequences of behavior become the causes of its subsequent occurrence, in the same way as an organism's adaptation to its current environment sets its capacity to reproduce and transmit its genetic and epigenetic organization."; "For behaviors, the reinforcement process corresponds to the survival criterion in natural selection. Depending on their consequences, behaviors differentially reproduce, that is, their future probability varies, much as the genetic pool of an organism is transmitted to the next generation through the number of offspring it breeds", and "the ongoing act-in-context can be selected, and can "reproduce" (can be repeated), provided that the context retains enough common characteristics with the initial context in which behavior first occurred and was reinforced." (Monestès, 2015, p. 101, 102);

"Evolution theory is concerned mainly with the study of phylogenetic adaptation-that is, the adaptation of a species to the environment across generations. Learning psychology, on the other hand, can be seen as the study of ontogenetic adaptation-that is, the adaptation of an individual organism to its environment during the lifetime of the individual." (De Houwer et al., 2013, p.633).

(A) Standard biological science model of genetic evolution in populations of individual organisms

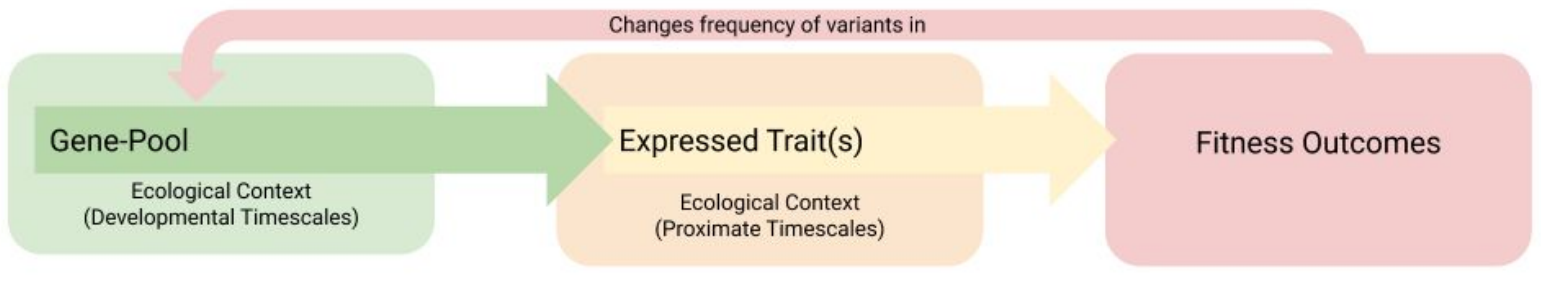

(B) Contextual behavioral science model of behavioral evolution within individuals as a population

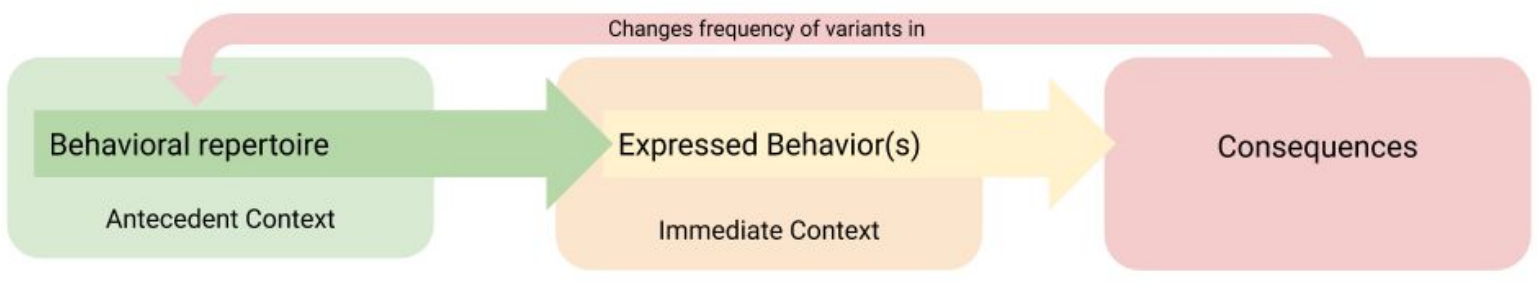

Fig. 2. Analogous conceptualizations of change in genetic evolution and behavioral evolution (adapted from Atkins et al., 2019, p.53). (A) Within the standard biological science model of genetic evolution (i.e. the Modern Synthesis), the gene-pool of a given population is expressed iteratively over developmental timescales within a particular ecological context. At any given point, the trait expression of an individual results in variant fitness outcomes, which, through relative differences in survival and reproduction, lead to changing frequency of genetic variants in the population.

(B) Within the contextual behavior science (CBS) model of behavioral evolution, an individual can be conceptualized as a population containing variant behavioral potentialities (a behavioral repertoire), the likelihood of any set of behavioral variants being expressed within a given context being a function of selection-by-consequence over (largely but not exclusively) developmental timescales. 
Thus, CBS has begun to embrace the concepts advanced by proponents of an EES (see above) of generalized notions of evolution, such as the inclusion of various streams and mechanisms of inheritance, and selection occurring at multiple levels of organization (Hayes et al., 2017; Hayes \& Sanford, 2015). The following quote represents how multi-level selection thinking informs CBS views on the individual: "Thinking of thoughts and rules virtually as life forms, and of personal repertoires as groups of these and other behavioral life forms, allows the analytic methods and insights of multi-level selection to be applied directly to the dynamics of [thought networks]. ... Peace of mind is an important human goal and multi-level selection should be able to help therapists produce it." (Hayes et al., 2017, p.319)

The analogy of individual as a population, shaped by the interactions of various traits and entities over time, which in turn shape the behavior and well-being of the whole organism, has also entered popular culture and classrooms through the Pixar Movie "Inside Out", which was itself informed by psychological science (Cannon, 2016).

In this regard, the conceptualizations of evolution stemming from the CBS seem to be of particular importance for education, since these conceptualizations directly inform approaches and methods for advancing social-emotional learning and psychotherapeutic interventions. For example, Hayes \& Ciarrochi (2015) have developed metaphors and methods designed to help adolescents develop a more flexible approach to difficult internal and external experiences, in essence giving them the tools to evolve behavioral repertoires that are in line with what they might care about, through processes of conscious variation and selection. Ciarrochi et al. (2016) advance specific policy recommendations for school contexts to promote health and well-being of students and teachers, informed by CBS and evolutionary concepts. Wilson et al. (2014) and Atkins et al. (2019) developed methods, informed by generalized evolutionary principles and CBS, that help groups of various scales and context evolve their group culture and behavioral repertoires towards group goals and values.

Interestingly, while CBS informs educational context through a range of research programs, the question of whether it can also inform educational curriculum content has apparently received little attention. Is it possible and conceivable that evolution education might be helpful in these endeavours by giving students and teachers the tools for conceptual understanding of these methods and the rationale behind them, including of the self as an evolving population (see Hanisch \& Eirdosh, 2020b)? In turn, the degree to which such metacognitive conceptual understanding might influence the impact of CBS methods and metaphors might be a research question of interest to both the education and CBS research community.

\section{Conceptual clarification of a generalized evolutionary theory}

Based on the previous discussions, this section presents an overview of how the concepts of evolutionary theory are currently characterized in a more gene-focused understanding stemming from the Modern Synthesis (as it also appears to be largely used in evolution 
education, see Hanisch \& Eirdosh, 2020c) vs. how these concepts are conceived in a more generalized, trait-focused, interdisciplinary, complex-systems, understanding of evolution by the various fields highlighted above.

Generally, evolution scientists and biology education researchers largely agree on a set of core concepts that make up the causal mechanisms leading to the evolutionary changes of populations. These are the concepts of variation, inheritance or transmission, selection through differential reproduction or other biases in multiplication and transmission, migration as well as more or less random processes such as drift. At the most basic level, evolutionary dynamics can be said to emerge when variation producing (and constraining) processes and frequency changing processes (Endler \& McLellan, 1988) act on a population over many iterations of a given trait-set. Furthermore, concepts like fitness and adaptation are used to describe the way that the workings of variation, selection and inheritance lead to the spread and persistence of certain characteristics and patterns relative to others in a population. However, there are differences in how narrowly or broadly all these concepts are understood, or what kinds of phenomena they are meant to describe.

Table 1 provides an overview of these different conceptualizations of core concepts in evolution, in a more gene-focused way and a more generalized way. Note that this table can only provide a selection of conceptual differences that we focus on in this article due to their proposed educational value (see Hanisch \& Eirdosh 2020b for an extended discussion of a range of hypothesized educational opportunities).

\section{Outlook}

What do the developments in interdisciplinary evolution science outlined in this paper mean for how we teach about evolution, in biology but also in other subject areas? Might these developments provide opportunities for advancing the understanding, acceptance or relevance of evolution, or might they in fact pose greater challenges for conceptual clarity in the future? Must these developments be actively incorporated to "keep up" with current science, or can these developments be safely put aside for various reasons?

Our aim is to encourage a wider discussion, within the evolution education community and other education communities, on these issues. We propose the need for an interdisciplinary research program that explicitly explores these areas of educational potential. Various content and teaching methods have been developed by us, with preliminary evidence of their usefulness for student learning in classrooms, to integrate more generalized perspectives of evolution into teaching about human evolution, human behavior, and sustainable development. 
Table 1: Comparison of gene-focused and phenotype-focused evolution models by key principles, processes and concepts of evolution.

\begin{tabular}{|c|c|c|}
\hline $\begin{array}{l}\text { Concept, Principle, } \\
\text { Process }\end{array}$ & Gene-focused conception of evolution & Phenotype-focused conception of evolution \\
\hline $\begin{array}{l}\text { What changes in a } \\
\text { population are primarily } \\
\text { being focused on? }\end{array}$ & $\begin{array}{l}\text { The frequency of genes/alleles (which } \\
\text { are involved in the expression of a } \\
\text { phenotype) }\end{array}$ & $\begin{array}{l}\text { The frequency of heritable traits, including genes, gene-regulation patterns, morphology, physiology, behavior, } \\
\text { cognition, symbols, developmental processes, life history traits, group-level traits (social organisation, norms, } \\
\text { institutions), technologies and structures made by organisms }\end{array}$ \\
\hline Examples & $\begin{array}{l}\text { genes involved in skin color, blood type, } \\
\text { Lactase-persistence alleles, FoxP2-gene }\end{array}$ & literacy, imitation, drinking milk, tattoos, mother tongue, length of childhood period, obesity \\
\hline $\begin{array}{l}\text { How do new variations of } \\
\text { traits come about? }\end{array}$ & $\begin{array}{l}\text { Through genetic mutation and } \\
\text { recombination; often conceptualized as } \\
\text { purely random }\end{array}$ & $\begin{array}{l}\text { Through various mechanisms, depending on the trait: genetic mutation and recombination; trial-and-error } \\
\text { learning, accidents, creativity, recombination of ideas; behavior change in response to new environments; } \\
\text { phenotypic plasticity; changes in developmental processes; and interactions between them; variation can be } \\
\text { more or less "random" or biased }\end{array}$ \\
\hline
\end{tabular}

How does selection of a The trait increases chances of survival trait occur?

The trait increases chances of survival and reproduction of the organism und
the given environmental conditions; usually conceptualized as unidirectional - the external environment selects a phenotype

\section{Through what other} mechanisms can changes in populations occur?

Random processes such as genetic drift; founder effects; migration; biased genetic inheritance due to meiotic drive genetic hitchhiking

How is a trait inherited, Through biological reproduction and transmitted, multiplied or inheritance of the genetic material to $\begin{array}{ll}\text { transmitted, multiplied or } & \text { inheritance } \\ \text { retained in the } & \text { offspring }\end{array}$ population?

What is the meaning of fitness?

Number of surviving offspring (fitness on the level of organisms); increasing frequency of alleles in a population (fitness on the level of genes/alleles/genotypes)

Where is information In the genome

Through various mechanisms, depending on the trait: increased chances of survival and reproduction (natural selection); conditioning, intrinsic motivations and preferences, social learning strategies or imitation biases leading the organism (consciously or unconsciously/intentionally or unintentionally) to learn, repeat, use, imitate, rebuild, or teach others (including concepts of cultural selection and biased transmission); complex causal interactions between these mechanisms

Random processes such as drift (genetic, cultural); founder effects; migration; biased transmission of traits due to cognitive/psychological factors; cultural linkage

conceptions

Ibanez (2020), Koops et al. (2014), Mesoud et al. (2013), Shennan (2009), Smaldino \& McElreath (2016), Street et al. (2017), Waring et al. (2017)

Carvalho et al. (2012), Jablonka \& Lamb (2005), Moczek et al. (2011), Pfennig et al. (2010), Reader et al. (2016), Scoville \& Pfrender (2010), Snell-Rood (2013), Sol (2003)

Hayes et al. (2017), Laland et al. (2015), Mesoudi (2011), Richerson \& Boyd (2005)

Through various mechanisms, depending on the trait: biological reproduction (genetic inheritance), transmission of gene-expression patterns (epigenetic inheritance); social learning and teaching, rebuilding, usage (behavioral and symbolic inheritance); accumulation and endurance of structures and artefacts in the environment (ecological inheritance); combinations and interactions between these mechanisms leading to developmental reconstruction of phenotypes; behavioral retention and reinforcement within organism

Number of surviving offspring (biological fitness on the level of organisms); any other relevant measure of "success" of individuals and benefits due to the trait (pay-off, utility; cultural fitness on the level of the organism); number of copiers (cultural fitness on the level of the trait, organism or group); increasing frequency of a trait or thing in a population (fitness on the level of the trait)

In genomes, gene regulation networks, neural networks, social networks, and the environment (structures, technologies)

On populations of individual organisms

On populations on many different levels of biological organisation, from genomes, to cells, to multicellular organisms, to groups of organisms, to ecosystems. The strength of evolutionary change can be different between these levels on a case by case basis, depending on functional integration and interdependence, affecting evolutionary trajectories. In fact the different levels of biological organisation had to evolve from lower levels in the first place, which requires a conception of evolution acting on multiple levels.

No, because the genome in germ cells does not change during the lifetime of an organism. Only populations can adapt.

Yes, because organisms are populations themselves consisting of multiple levels of variation and selection processes, including open-ended processes of behavior change and reinforcement, in turn potentially affecting other traits. Such changes can also be transmitted to others and lead to adaptations on the level of populations.
Mesoudi (2011), Richerson \& Boyd (2005), Yeh et al. (2019)

Bonduriansky (2012), Hayes et al. (2017) Hoppitt \& Laland (2013), Jablonka \& Lamb (2005), Odling-Smee \& Laland (2011), Oyama et al. (2001)

Bowles \& Gintis (2011), Borgerhoff Mulder \& Schacht (2012), Richerson \& Boyd (2005) Okasha (2006)

Jablonka \& Szathmáry (1995), Szathmáry (2015), Sweller \& Sweller (2006)

Aktipis (2016), Greaves (2018), Gregory et al. (2016), Hayes \& Sanford (2015), Ibanez (2020), Kline et al. (2018), Okasha (2006), Smith \& Szathmáry (1995), Sober \& Wilson (1998), Turchin (2010), Wilson (2015)

Hayes \& Sanford (2015), Hayes et al. (2017), Monestès (2015) 


\section{Abbreviations}

MS - Modern Synthesis

EES - Extended Evolutionary Synthesis

CES - Cultural Evolution Science

CBS - Contextual Behavioral Science

\section{References}

Acerbi, A., \& Mesoudi, A. (2015). If we are all cultural Darwinians what's the fuss about? Clarifying recent disagreements in the field of cultural evolution. Biology and Philosophy, 30(4), 481-503. https://doi.org/10.1007/s10539-015-9490-2

Aktipis, A. (2016). Principles of cooperation across systems: From human sharing to multicellularity and cancer. Evolutionary Applications, 9(1), 17-36. https://doi.org/10.1111/eva.12303

Aplin, L. M. (2019). Culture and cultural evolution in birds: a review of the evidence. Animal Behaviour, 147, 179-187. https://doi.org/10.1016/j.anbehav.2018.05.001

Apodaca, M. J., Mclnerney, J. D., Sala, O. E., Katinas, L., \& Crisci, J. V. (2019). A Concept Map of Evolutionary Biology to Promote Meaningful Learning in Biology. The American Biology Teacher, 81(2), 79-87. https://doi.org/10.1525/abt.2019.81.2.79

Atkins, P. W. B., Wilson, D. S., \& Hayes, S. C. (2019). Prosocial. Using Evolutionary Science to Build Productive, Equitable, and Collaborative Groups. Oakland, CA, USA: Context Press.

Arthur, J., Kristjansoon, K., and Thoma, S. (2016). Is Grit the Magic Elixir of Good Character? Some Reflections on Angela Duckworth's New Book, GRIT: The Power of Passion and Perseverance, 1-9.

Baedke, J., Fábregas-Tejeda, A., \& Vergara-Silva, F. (2020). Does the extended evolutionary synthesis entail extended explanatory power? Biology and Philosophy, 35(1), 1-22.

https://doi.org/10.1007/s10539-020-9736-5

Bapteste, E., \& Huneman, P. (2018). Towards a Dynamic Interaction Network of Life to unify and expand the evolutionary theory. BMC Biology, 16(56), 1-16.

Beinhocker, E. D. (2006). The origin of wealth. Evolution, complexity, and the radical remaking of economics. Boston, MA, USA: Harvard Business School Press.

Bonduriansky, R. (2012). Rethinking heredity, again. Trends in Ecology and Evolution, 27(6), 330-336. https://doi.org/10.1016/j.tree.2012.02.003

Borgerhoff Mulder, M., \& Schacht, R. (2012). Human Behavioural Ecology. ELS, (October). https://doi.org/10.1002/9780470015902.a0003671.pub2

Bowles, S., \& Gintis, H. (2011). A Cooperative Species. Human reciprocity and its evolution. Princeton, New Jersey, USA: Princeton University Press.

Boyd, R., \& Richerson, P. (1985). Culture and the Evolutionary Process. Chicago, USA: University of Chicago Press. 
Boyd, R. T., \& Richerson, P. J. (2005). The Origin and Evolution of Cultures. Oxford: Oxford University Press.

Cannon, B. (2016). Inside Out: Behind-the-Scenes Science With Dacher Keltner, PhD. Psi Chi, 20(3), 20-23. https://doi.org/10.24839/1092-0803.eye20.3.20

Carvalho, S., Biro, D., Cunha, E., Hockings, K., McGrew, W. C., Richmond, B. G., \& Matsuzawa, T. (2012). Chimpanzee carrying behaviour and the origins of human bipedality. Current Biology, 22(6),

R180-R181. https://doi.org/10.1016/j.cub.2012.01.052

Cavalli Sforza, L. L., \& Feldman, M. W. (1973). Cultural versus biological inheritance: phenotypic transmission from parents to children (a theory of the effect of parental phenotypes on children's phenotypes). American Journal of Human Genetics, 25(6), 618-637. Retrieved from

https://www.ncbi.nlm.nih.gov/pmc/articles/PMC1762580/\#

Cavalli-Sforza, L. L., \& Feldman, M. W. (1981). Cultural Transmission and Evolution: A Quantitative Approach. Princeton, New Jersey, USA: Princeton University Press.

Ciarrochi, J., Atkins, P. W. B., Hayes, L. L., Sahdra, B. K., \& Parker, P. (2016). Contextual positive psychology: Policy recommendations for implementing positive psychology into schools. Frontiers in Psychology, 7(OCT), 1-16. https://doi.org/10.3389/fpsyg.2016.01561

Davies, J. (2014). A closed loop. The DNA helix gave 20th-century biology its symbol. But the more we learn, the more life circles back to an older image.

https://aeon.co/essays/the-feedback-loop-is-a-better-symbol-of-life-than-the-helix

De Houwer, J., Barnes-Holmes, D., \& Moors, A. (2013). What is learning? On the nature and merits of a functional definition of learning. Psychonomic Bulletin \& Review, 20, 631-642.

https://doi.org/10.3758/s13423-013-0386-3

Dobzhansky, T. (1973). Nothing in Biology Makes Sense except in the Light of Evolution. The American Biology Teacher, 35(3), 125-129. https://doi.org/10.2307/4444260

Endler, J. A., \& McLellan, T. (1988). The processes of evolution: toward a newer synthesis. Annual Review of Ecology and Systematics, 19, 395-421.

https://doi.org/10.1146/annurev.es.19.110188.002143

Fábregas-Tejeda, A. (2019). New Perspectives on Theory Change in Evolutionary Biology. Journal for General Philosophy of Science, (0123456789). https://doi.org/10.1007/s10838-019-09466-6

Fix, B. (2019). New Microeconomics: How Evolution Explains Resource Distribution. Evonomics. https://evonomics.com/an-evolutionary-theory-of-resource-distribution/

Gintis, H. (2009). The Bounds of Reason. Game Theory and the Unification of the Behavioral Sciences. Princeton, Oxford: Princeton University Press.

Greaves, M. (2018). Nothing in cancer makes sense except... BMC Biology, 16(1), 1-8. https://doi.org/10.1186/s12915-018-0493-8

Gregory, T. R., Elliott, T. A., \& Linquist, S. (2016). Why Genomics Needs Multi-Level Evolutionary Theory. In N. Eldredge, T. Pievan, E. Serrell, \& I. Tëmkin (Eds.), Evolutionary Theory: A Hierarchical Perspective (pp. 137-150). Chicago, USA: University of Chicago Press. 
Hanisch, S., \& Eirdosh, D. (2020a). Conceptual clarification of evolution as an interdisciplinary science. Preprint.

Hanisch, S., \& Eirdosh, D. (2020b). Educational potential of teaching evolution as an interdisciplinary science. Preprint.

Hanisch, S., \& Eirdosh, D. (2020c). Challenges with conceptualizations of evolution in biology education. Preprint.

Hanisch, S., \& Eirdosh, D. (2020d). Potential objections to teaching evolution as an interdisciplinary science. Preprint.

Hayes, L. L., \& Ciarrochi, J. (2015). The thriving adolescent. Using Acceptance and Commitment Therapy and Positive Psychology to help teens manage emotions, achieve goals, and build connections. Oakland, CA, USA: Context Press.

Hayes, S. C., Strosahl, K. D., \& Wilson, K. G. (2012). Acceptance and Commitment Therapy. The Process and Practice of Mindful Change (2nd ed.). New York, NY, USA: The Guilford Press.

Hayes, S. C., \& Sanford, B. T. (2015). Modern psychotherapy as a multidimensional multilevel evolutionary process. Current Opinion in Psychology, 2(May), 16-20.

https://doi.org/10.1016/j.copsyc.2015.01.009

Hayes, S. C., Sanford, B. T., \& Chin, F. T. (2017). Carrying the baton: Evolution science and a contextual behavioral analysis of language and cognition. Journal of Contextual Behavioral Science, 6(3), 314-328. https://doi.org/10.1016/j.jcbs.2017.01.002

Hodgson, G. M., \& Knudsen, T. (2010). Darwin's Conjecture. The search for general principles of social and economic evolution. Chicago, USA: University of Chicago Press.

Hoppitt, W., \& Laland, K.N., (2013). Social Learning: An Introduction to Mechanisms, Methods, and Models, Vol. 5. Princeton University Press, Princeton, NJ.

Huneman, P., \& Walsh, D. M. (2017). Challenging the Modern Synthesis. Adaptation, Development, and Inheritance. (P. Huneman \& D. M. Walsh, Eds.). New York, NY, USA: Oxford University Press.

https://doi.org/10.1093/oso/9780199377176.001.0001

Huxley, J. (1943). Evolution, the modern synthesis. New York ; London: Harper \& brothers.

Ibanez, S. (2020). The Evolution of Ecosystem Phenotypes. Biological Theory, (0123456789).

https://doi.org/10.1007/s13752-020-00345-8

Jablonka, E., \& Lamb, M. J. (2005). Evolution in Four Dimensions. Genetic, Epigenetic, Behavioral, and Symbolic Variation in the History of Life. Cambridge, MA, USA: MIT Press.

Jablonka, E., \& Szathmáry, E. (1995). The evolution of information storage and heredity. Trends in Ecology \& Evolution (Personal Edition), 10(5), 206-211.

https://doi.org/10.1016/S0169-5347(00)89060-6

Kline, M. A., Waring, T. M., \& Salerno, J. (2018). Designing cultural multilevel selection research for sustainability science. Sustainability Science, 13(1), 9-19.

https://doi.org/10.1007/s11625-017-0509-2 
Koops, K., Visalberghi, E., \& Van Schaik, C. P. (2014). The ecology of primate material culture. Biology Letters, 10(11), 3-6. https://doi.org/10.1098/rsbl.2014.0508

Laland, K. N., Uller, T., Feldman, M. W., Sterelny, K., Müller, G. B., Moczek, A. P., ... Odling-Smee, J. (2015). The extended evolutionary synthesis: its structure, assumptions and predictions. Proc. R. Soc. B, 282(1813), 20151019. https://doi.org/10.1098/rspb.2015.1019

Laland, K. N., Uller, T., Feldman, M., Sterelny, K., Müller, G. B., Moczek, A. P., ... Strassmann, J. E. (2014). Does Evolutionary Theory Need A Rethink. Nature, 514, 161-164. https://doi.org/10.1038/514161a

Lewens, T. (2019). The Extended Evolutionary Synthesis: what is the debate about, and what might success for the extenders look like ? Biological Journal of the Linnean Society, 127(4), 707-721. Retrieved from https://doi.org/10.1093/biolinnean/blz064

Love, A. C. (2017). Evo-Devo and the Structure(s) of Evolutionary Theory. A Different Kind of Challenge. In P. Huneman \& D. M. Walsh (Eds.), Challenging the Modern Synthesis: Adaptation, Development, and Inheritance. Oxford Scholarship Online.

https://doi.org/10.1093/oso/9780199377176.003.0005

McElreath, R., \& Boyd, R. T. (2007). Mathematical Models of Social Evolution. A Guide for the Perplexed. Chicago, USA: University of Chicago Press.

Mesoudi, A. (2007). Biological and Cultural Evolution: Similar but Different. Biological Theory, 2(2), 119-123. https://doi.org/10.1162/biot.2007.2.2.119

Mesoudi, A. (2011). Cultural Evolution: How Darwinian Theory Can Explain Human Culture and Synthesize the Social Sciences. Chicago, USA: University of Chicago Press.

Mesoudi, A., Whiten, A., \& Laland, K. N. (2006). Towards a unified science of cultural evolution. Behavioral and Brain Sciences, 29(4), 329-347. https://doi.org/10.1017/S0140525X06009083

Mesoudi, A., Laland, K. N., Boyd, R. T., Buchanan, B., Flynn, E., McCauley, R. N., ... Tennie, C. (2013). The Cultural Evolution of Technology and Science. In P. J. Richerson \& M. H. Christiansen (Eds.), Cultural Evolution: Society, Technology, Language and Religion (Vol. 12, pp. 193-216). Cambridge, MA, USA: MIT Press. Retrieved from http://lalandlab.st-andrews.ac.uk/files/2015/08/Publication202.pdf

Moczek, A. P., Sultan, S., Foster, S., Ledón-Rettig, C., Dworkin, I., Nijhout, H. F., ... Pfennig, D. W. (2011). The role of developmental plasticity in evolutionary innovation. Proceedings of the Royal Society B: Biological Sciences, 278(1719), 2705-2713. https://doi.org/10.1098/rspb.2011.0971

Monestès, J.-L. (2015). A Functional Place for Language in Evolution. In R. D. Zettle, S. C. Hayes, D. Barnes-Holmes, \& A. Biglan (Eds.), The Wiley Handbook of Contextual Behavioral Science (pp. 100-114). Wiley \& Sons. https://doi.org/10.1002/9781118489857.ch7

Müller, G. B. (2017). Why an extended evolutionary synthesis is necessary. Interface Focus, 7(5). https://doi.org/10.1098/rsfs.2017.0015

Noble, D. (2015). Evolution beyond neo-Darwinism: a new conceptual framework. The Journal of Experimental Biology, 218, 7-13. https://doi.org/10.1242/jeb.106310

Noble, D. (2006). The Music of Life. Biology beyond the Genome. Oxford: Oxford University Press. 
Odling-Smee, J., Laland, K. N., \& Feldman, M. W. (2003). Niche construction. The neglected Process in Evolution. Princeton, New Jersey, USA: Princeton University Press.

Odling-Smee, J., \& Laland, K. N. (2011). Ecological Inheritance and Cultural Inheritance: What Are They and How Do They Differ? Biological Theory, 6(3), 220-230.

https://doi.org/10.1007/s13752-012-0030-x

Okasha, S. (2006). Evolution and the levels of selection. Oxford: Oxford University Press.

Oyama, S., Griffiths, P. E., \& Gray, R. D. (2001). Cycles of contingency. Developmental Systems and Evolution. Cambridge, MA, USA: MIT Press.

Pfennig, D. W., Wund, M. A., Snell-Rood, E. C., Cruickshank, T., Schlichting, C. D., \& Moczek, A. P. (2010). Phenotypic plasticity's impacts on diversification and speciation. Trends in Ecology and Evolution, 25(8), 459-467. https://doi.org/10.1016/j.tree.2010.05.006

Pigliucci, M. (2009). An extended synthesis for evolutionary biology. Annals of the New York Academy of Sciences, 1168, 218-228. https://doi.org/10.1111/j.1749-6632.2009.04578.x

Pigliucci, M., \& Müller, G. B. (2010). Evolution - The extended synthesis. (M. Pigliucci \& G. B. Müller, Eds.). Cambridge, MA, USA: MIT Press.

Reader, S. M., Morand-Ferron, J., \& Flynn, E. (2016). Animal and human innovation: novel problems and novel solutions. Philosophical Transactions of the Royal Society B: Biological Sciences, 371(1690), 20150182. https://doi.org/10.1098/rstb.2015.0182

Rees, W. (2010). What 's blocking sustainability? Human nature, cognition, and denial. Sustainability: Science, Practice and Policy, 6(2). https://doi.org/10.1080/15487733.2010.11908046

Rice, S. H. (2004). Evolutionary theory: mathematical and conceptual foundations. Sinauer Associates.

Richerson, P. J., \& Boyd, R. T. (2005). Not by Genes Alone. How Culture Transformed Human Evolution. Chicago, USA: University of Chicago Press.

Richerson, P. J., \& Christiansen, M. H. (2013). Cultural Evolution: Society, Technology, Language, and Religion. (P. J. Richerson \& M. H. Christiansen, Eds.). Cambridge, MA, USA: MIT Press. https://doi.org/10.7551/mitpress/9780262019750.001.0001

Scoville, A. G., \& Pfrender, M. E. (2010). Phenotypic plasticity facilitates recurrent rapid adaptation to introduced predators. Proceedings of the National Academy of Sciences, 107(9), 4260-4263. https://doi.org/10.1073/pnas.0912748107

Shennan, S. J. (2009). Pattern and Process in Cultural Evolution. (S. J. Shennan, Ed.). Berkeley, California, USA: University of California Press.

Sheppard, C. E., Marshall, H. H., Inger, R., Thompson, F. J., Vitikainen, E. I. K., Barker, S., ... Cant, M. A. (2018). Decoupling of Genetic and Cultural Inheritance in a Wild Mammal. Current Biology, 28(11), 1846-1850.e2. https://doi.org/10.1016/i.cub.2018.05.001

Skinner, B. F. (1953). Science and Human Behavior. New York, USA: Macmillan. 
Smaldino, P. E., \& McElreath, R. (2016). The natural selection of bad science. R. Soc. Open Sci., 3(160384). https://doi.org/10.1098/rsos.160384

Smith, J. M., \& Szathmáry, E. (1995). The Major Transitions in Evolution. New York, NY, USA: Oxford University Press.

Snell-Rood, E. C. (2013). An overview of the evolutionary causes and consequences of behavioural plasticity. Animal Behaviour, 85(5), 1004-1011. https://doi.org/10.1016/j.anbehav.2012.12.031

Sober, E., \& Wilson, D. S. (1998). Unto Others. The Evolition and Psychology of Unselfish Behavior. Cambridge, MA, USA: Harvard University Press. https://doi.org/10.1093/mind/111.441.178

Sol, D. (2003). Behavioural Innovation: A Neglected Issue in the Ecological and Evolutionary Literature? In S. M. Reader \& K. N. Laland (Eds.), Animal Innovation. Oxford Scholarship Online. https://doi.org/10.1093/acprof:oso/9780198526223.001.0001

Stern, J., Ferraro, K., \& Mohnkern, J. (2017). Tools for teaching conceptual understanding, secondary: Designing lessons and assessments for deep learning. Corwin Press.

Street, S. E., Navarrete, A. F., Reader, S. M., \& Laland, K. N. (2017). Coevolution of cultural intelligence, extended life history, sociality, and brain size in primates. Proceedings of the National Academy of Sciences, 114(30), 7908-7914. https://doi.org/10.1073/pnas.1620734114

Sweller, J., \& Sweller, S. (2006). Natural information processing systems. Evolutionary Psychology, 4, 434-458. https://doi.org/10.1177/147470490600400135

Szathmáry, E. (2015). Toward major evolutionary transitions theory 2.0. Proceedings of the National Academy of Sciences of the United States of America, 112(33), 10104-10111.

https://doi.org/10.1073/pnas.1421398112

Turchin, P. (2010). Warfare and the Evolution of Social Complexity: A Multilevel-Selection Approach. Structure and Dynamics, 4(3).

Valiant, L. (2013). Probably Approximately Correct: Nature's Algorithms for Learning and Prospering in a Complex World. Basic Books.

Waring, T. M., Geoff, S. H., \& Smaldino, P. E. (2017). The coevolution of economic institutions and sustainable consumption via cultural group selection. Ecological Economics, 131, 524-532. https://doi.org/10.1016/i.ecolecon.2016.09.022

West-Eberhard, M. J. (2003). Developmental Plasticity and Evolution. New York, NY, USA: Oxford University Press.

Whiten, A., Hinde, R. A., Laland, K. N., \& Stringer, C. B. (2011). Culture evolves. Philosophical Transactions of the Royal Society B: Biological Sciences, 366(1567), 938-948.

https://doi.org/10.1098/rstb.2010.0372

Whiten, A., \& van Schaik, C. P. (2007). The evolution of animal "cultures" and social intelligence. Philosophical Transactions of the Royal Society B-Biological Sciences, 362(1480), 603-620. https://doi.org/10.1098/rstb.2006.1998

Wilson, D. S. (2015). Does Altruism exist? Culture, Genes, and the Welfare of Others. New Haven, CT, USA: Yale University Press. 
Wilson, D. S., Hayes, S. C., Biglan, A., \& Embry, D. D. (2014). Evolving the Future: Toward a Science of Intentional Change. The Behavioral and Brain Sciences, 37(4), 395-460.

https://doi.org/10.1017/S0140525X13001593

Wilson, D. S., \& Johnson, E. M. (2016). Toward A New Social Darwinism. Evolution Institute. Retrieved from: https://evolution-institute.org/toward-a-new-social-darwinism/

Wray, G. A., Hoekstra, H. E., Futuyma, Douglas J. , Lenski, Richard E. , Mackay, Trudy F. C. , Schluter, D. \& Strassmann, Joan E. (2014). Does evolutionary theory need a rethink? No, all is well. Nature, 514, 161-164. https://doi.org/10.1038/514161a

Yeh, D. J., Fogarty, L., \& Kandler, A. (2019). Cultural linkage: the influence of package transmission on cultural dynamics. Proc. R. Soc. B, 286(20191951). Retrieved from

http://dx.doi.org/10.1098/rspb.2019.1951 